\title{
Application of Monte Carlo simulation and PERT/CPM techniques in planning of construction projects: A Case Study
}

\author{
Mertcan Karabulut \\ Industrial Engineering, International University of Sarajevo
}

\begin{tabular}{l} 
Article Info \\
\hline Article history: \\
Received Oct $3^{\text {th }}, 2017$ \\
Revised Dec $10^{\text {th }}, 2017$ \\
Accepted Dec $15^{\text {th }}, 2017$ \\
\hline Keyword: \\
Critical Path Method \\
Monte Carlo Simulation \\
Gantt Chart \\
Risk Analysis \\
Luxury Villa
\end{tabular}

\begin{abstract}
Construction project scheduling and monitoring is challenging in today's very dynamic business environment. In this study, a project execution tracking system in a medium-sized construction company was studied. Two different methods were proposed as problem solution for project scheduling and monitoring. Traditional CPM and PERT methods, and Monte Carlo simulation as risk analysis tool were used in this case study. The results show that 186 working days (which is optimistic estimate) is required to finish a luxury villa is determined by CPM method, while Monte Carlo simulation implies that there is $50 \%$ of chance that the luxury villa will be done in 205 days, but still there is a risk of $50 \%$ that the villa construction may be delayed.
\end{abstract}

Corresponding Author: Mertcan KARABULUT

International University of Sarajevo

Email: sansimya@hotmail.com

\section{Introduction}

Completing any project on time with the determined project cost is not always easy job for any project manager. Although, project management techniques and tools are very efficient and motivating for the establishment of many project, still there are still common mistakes which leads a complication in a project. There are many factors which causes complexity such as, lack of analyzing risk factors, manager mistakes, internal and external factors, usage of the only one technique without comparison with other tools and techniques and labor-force factors.

These factors play a significant role in the establishment of a project. Therefore, in long term these kind of complications causes problems for completion time, budget-cost arrangements, correct usage of labor-force and resources. Therefore, the proper usage of fine constructed project management tools and techniques are key factors for the establishment of proper project within a proportional budget and resource to be completed in a planned time interval. In this article, the work system of the construction company will be explored and investigated due to problem of monitoring the work system. The Mehmet's construction company was established in 2001 in Ankara. 
The company is very comprehensive and based on construction along with project control. The company is carrying on a business in several cities in Turkey as well as at abroad [1]. The company is serving at abroad as well in such countries, Libya, Iraq, Syria and Afghanistan. The company is constructing a various type of housing such as dormitories for the students, hospitals private or the public, luxury residential or intermediate houses, hotels for touristic purposes as well as small apartments for the use of local people, educational buildings, and workshops. The most important objective of the company is awareness by whole market and perceived. The problem of the company is an inability of having a system in which current business can be properly monitored and controlled.

The current work system of the company is based on old-fashioned methods which prevents the development of the company below the expectations. Nowadays it is not easy for a construction company to do all the work by order because the possibilities of many types of error which are undesirable.

For Mr. Mehmet's company, there is a significant problem for keeping track of the business which puts the company in hard circumstances. There are no project management techniques which should be used to lower the hardness of the works in the company, hence the company is struggling each time due to lack of project management tools. There are always causes and effects in every problem and the existence of the problem is the reflection of the primary causes. Those causes are time management, change management, cost management and project status.

The inability of managing the time, the lack of cost management method, the technical incompetence of the company for sudden alterations and the inevitable hardship of representing processes by diagrams, charts, or any other proper tool puts the company in a hard time for monitoring the status of the project. Energy efficiency plays one of the major roles in the construction by using proper energy efficient building components [2] [3] in various construction phases, such as first and second floor works along with roof works [4]. It is very long process, most importantly after the construction is done, construction work delivery must be in a good quality and produced components built in the house should be produced as it was reported in [5], to have better interior and exterior finish. Critical Path Method and Project Evaluation and Review Technique are very effective and mostly used methods in the history of the project management. By the establishment of these two methods, it does provide many benefit to its project managers such as deterministic times for three different time values.

In addition, for all the activities times can be found using these two algorithm such as the earliest and latest time where can a task begin or the latest or earliest time where can an activity completed along with slack time, which is the differences between start and finish times. These two methods are very effective way of illustrating the critical path and complete project duration. Thanks to these two approaches, any project can be managed and monitored easily on determined completion time of a project [6]. Another method used is Monte Carlo simulation to identify the project completion date by every possible combination of uncertain activities. While CPM and PERT methods gives the deterministic completion date for the project, Monte Carlo simulation gives the completion date based on probabilistic approach for the whole combined uncertain events. Critical Path Method does not consider the possible risk which might occur in the process of construction while Monte Carlo Simulation is taking account of every possible risks which may occur in the phases of construction which will directly affect the completion date of construction. In order to better understand and making comparison between these two methods, identification of possible risks and visual representation of those risks have a cruel role in the final result.

The quality of the deliverables and the whole system of project monitoring and executing is importan aspect of customer satisfaction for innovation areas sucas product, process, and administration. To achive this soft and hard toools are used suc as strategic planing, customer focus, employee involvement and trainings; and continious improvement standardizarion and measurment [7]. The overall goal of the company is to continuously improve monitoring of the project completion and improve deliverables by applying one of the quality initiatives [8][9].

The following section called as methods and techniques will be explored and investigated for the comparison of completion date for the Critical Path and Monte Carlo Simulation methods. 


\section{Methods, Techniques and Tools}

Project planning and scheduling methods proposed for Mehmet's company are based on these three project objectives: scope, schedule and budget. Before the establishment of any method for any project, the project triple constraints must be understood carefully for a better understanding of forthcoming methods. There are certain constraints which are fulfilled in every project as following, cost, schedule and time which represents the triangle shown below to satisfy the quality of the deliverable outcome. One constraint cannot be whole before another satisfies. The following Figure 1 represents the triple constraints of project management.

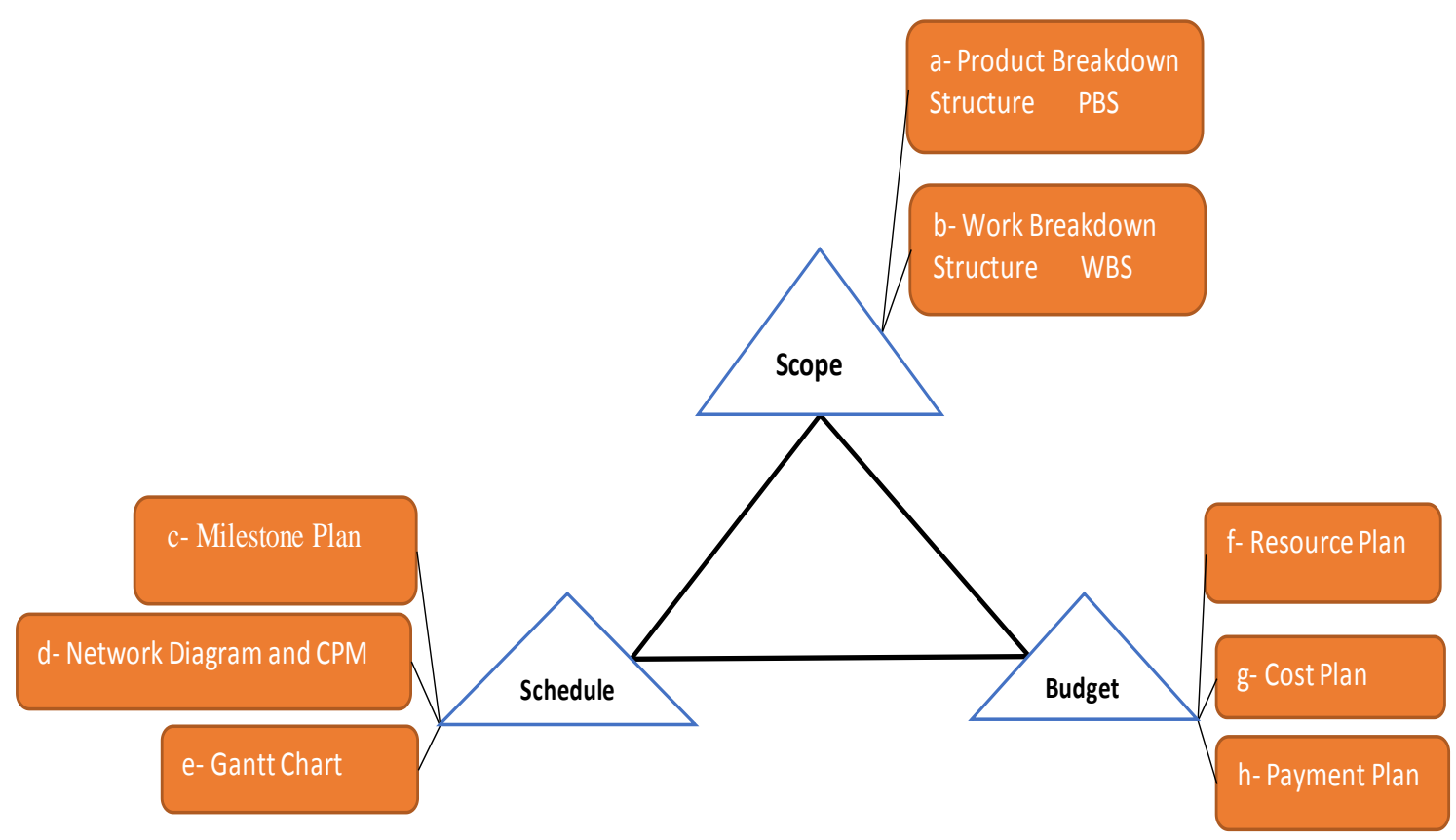

Figure 1: Project Objectives

After the explanation of Project Triple Constraints, in the following headings, the methods and tools which will be conducted in the establishment of Critical Path Algorithm and Monte Carlo simulation well be mentioned along with necessary formulas.

\section{1) Scope}

\section{PBS (Product Breakdown Structure)}

For better representation of activities of any particular project, the Product Work Breakdown structure is used to illustrate the activities in hierarchical order which generate the whole project with easier representation for the users. There are many ways to use PBS structure for the purposes of examining and authenticating [10].

\section{WBS (Work Breakdown Structure)}

Work Breakdown Structure (WBS) is the exact opposite way of creating a hierarchical structure of Product Work Breakdown Structure. In this method, project is divided into primary elements in order to show the project which is defining the scope of the project. It is very good representation for the users in which easy way of understanding the scope for, what is exactly needs to be done. Work Breakdown Structure is very effective tool in Project Management [11].

\section{2) Schedule}

\section{Milestone Plan}

Milestones in project management are activities which are representing the key events of a project and they are most important activities to achieve to finish the project. The project milestone has no duration which indicates the importance of activity. 


\section{Network Diagram and CPM (Critical Path Method)}

There are many areas of the usage for network diagrams which was created in the intention of making the project more manageable form for the users. Network diagram is mostly used for projects to be scheduled. Network diagram is representing the associations among the activities of any project for easier understanding [12]. Model of network diagram is shown in Figure 2.

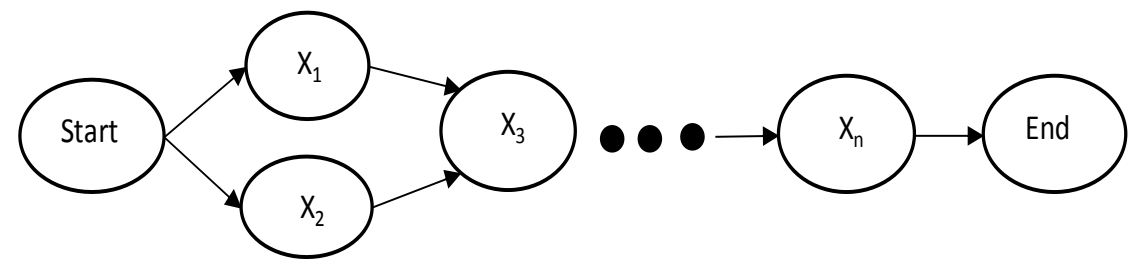

Figure 2: Network diagram model

On the network diagram, durations of some activities are given also their start and end time can be found using the network diagram. There is a special order in the sequence of network diagram, activities are arranged according to their predecessors. There is a formula to estimate the duration of the project by the expected time (TE) of the activities according to each activity optimistic and pessimistic times based on Beta distribution.

$$
T E=\frac{a+4 m+b}{6}
$$

where, $a$ represents the optimistic estimate, $m$ represents the most likely estimate and where $b$ represents the pessimistic estimate.

The visual representation of the Earliest Finish, Earliest Start, Latest Start, Latest Finish, Slack Time with corresponding form of usage in a network diagram with basic formulas is shown in the Figure 3 below.

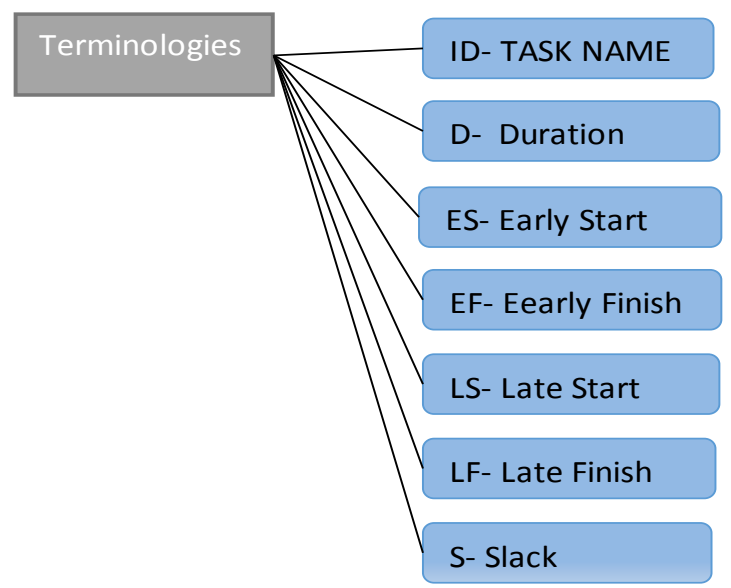

\begin{tabular}{|l|l|l}
\hline ES & ID & EF \\
\hline S & & S \\
\hline LS & D & LF \\
\hline
\end{tabular}

Figure 3: Terminologies for Network Diagram with corresponding form

Earliestfinish time $(E F)$ for $j-t h$ activity was determined as:

$$
E F_{j}=E S_{j}+T E_{j}
$$

where, $E S_{j}$ is earliest start time, while $T E_{j}$ is estimated time for $j-t h$ activity. 
Earlies start time (ES) for $j-t h$ activity was determined as:

$$
E S_{j}=\max \left(E F_{j}\right)
$$

where, $E F_{j}$ is maximum earliest finish time from the predecessor for $j-t h$ activity.

Completion time for the last activity represent project completion time $(\mu)$ and it was determined as:

$$
\mu=E F
$$

To find critical activity and determine critical path, backward path was calculated. Treterore, earliest finish time for the last activity becomes lates finish.

$$
L F=E F
$$

Latest start time (LS) for $j-t h$ activity was determined as:

where, $L F_{j}$ is latest finish time for $j-t h$ activity.

$$
L S_{j}=L F_{j}-T E_{j}
$$

Latest finish time $(L F)$ for $j-$ th activity was determined as:

$$
L F_{j}=\min \left(L S_{j}\right)
$$

where, $L S_{j}$ is minimum latest start time of successor activity.

Slack time calculation helps to determine critical path activities

Slack of activity $j=L S_{j}-E S_{j}$

where, $L S_{j}$ latest finish time for $j-t h$ activity

Activities with zero clack time represent critical path activities.

After calculation, the critical path by the given formula above, the next step is to find standard activity variances to be able to calculate uncertainity of a project completion [12].

$$
\sigma^{2}=\frac{(a-b)^{2}}{6}
$$

where, $a$ represents the optimistic duration and $b$ represents the pessimistic duration of an activity. While project variance is determined as sum of variances on the critical apath activities:

$$
\sigma_{p}^{2}=\sum \text { (variances of activitiees on critical path) }
$$

Square root of the project variance gives the standard deviation of the project duration.

$$
\sigma_{p}=\sqrt{\sigma_{p}^{2}}
$$

PERT uses the following assumptions to determine probability of project completion time: project duration follows a normal probability distribution, while activity times are statistically independent. Therefore, with these assumptions it is possible to determine probability of the project completion earlier or lather $\mu$, and standar normal equation can be applied.

$$
Z=\frac{x-\mu}{\sigma_{p}}
$$

In order to finish any project at the desired time, the formula above was used, where $\mu$ is estimated project duration time, $X$ is given time and $\sigma_{p}$ is project variance.

\section{Gantt Chart}


The Gantt chart shows planned and actual progress for many tasks displayed as bars against a horizontal time scale. It is a particularly effective and easy-to-read method of indicating the actual status for each of a set of tasks compared to the planned progress for each item of the set[13]. Sample of Gantt chart is shown in Figure 5.

\section{CPM (Critical Path Method)}

In order to identify the activities in the network diagram, to know which one is critical and which one is not, Critical Path Method were used for analyzing. Critical path method is a common project management technique which has been using for a long time. Especially for the projects which consist of dozens of activities. Therefore, Critical Path Method is a very effective project management technique which is used to identify important activitiesInvalid source specified.

\section{3) Budget}

The budget was estimated according to historical data and using three-pointestimate as well as using quotation system.

\section{Swott Analysis}

In order to make a proper analyze for any project, the Swott analysis is very effective and required tool to be conducted. Because, thanks to the properties of the Swott analysis, it gives an overall analysis for the strengths, weaknesses, opportunities and threats of any organizations. For clear understanding, there are internal and external factors in the Swott analysis, internal factors are the strengths and weaknesses of the organization and external factors are opportunities and threats of the organization.

These factors were identified and analyzed for the determination of what is preventing a workstation from its objectives and what is contributing to achieve the desired goal of the company. Therefore, Swott analysis is assisting for the workstation to operate more efficiently [14].

\section{Monte Carlo Simulation}

Monte Carlo Simulation has very long usage area in very Project management aspects like industrial purpose, scientific purpose, and logistical purpose. Monte Carlo Simulation was used in order to estimate the completion date of the project and the overall cost of the project with every doable integration of undetermined activity run. Monte Carlo simulation takes the deterministic times obtained and put them in long repeatable trials by iterating over long repeat of durations.

These coincidental values for each probabilistic distribution were used to estimate the completion time for a project with different durations between some frequencies. All possible risks which may delay the project completion date is considered in these combinations of trials [15].

To perform Monte Carlo simulation for luxury villa case the following steps were taken and the process is shown in Figure 4:

1) Quantitative model definition for project duration as $y=f\left(x_{1}, x_{2}, \ldots, x_{j}, \ldots, x_{n}\right)$, where $x_{j}$ is $j-t h$ activity duration, and $n$ is number of activities.

2) Random variables generation for $i$ - th run and $j$ - th activity (where $i=1$ to $k$, while $k$ is number of iterations).

3) Estimate of $x i_{1}, x i_{2}, \ldots, x i_{n}$ activity duration as well as project duration $y_{i}$ for $i-t h$ run.

4) Storage of the model and output in $y_{i}$.

5) Steps (2) and (3) were repeated for $k$ times.

6) The results were analyzed and graphically represented using probability density function and cumulative density function. 


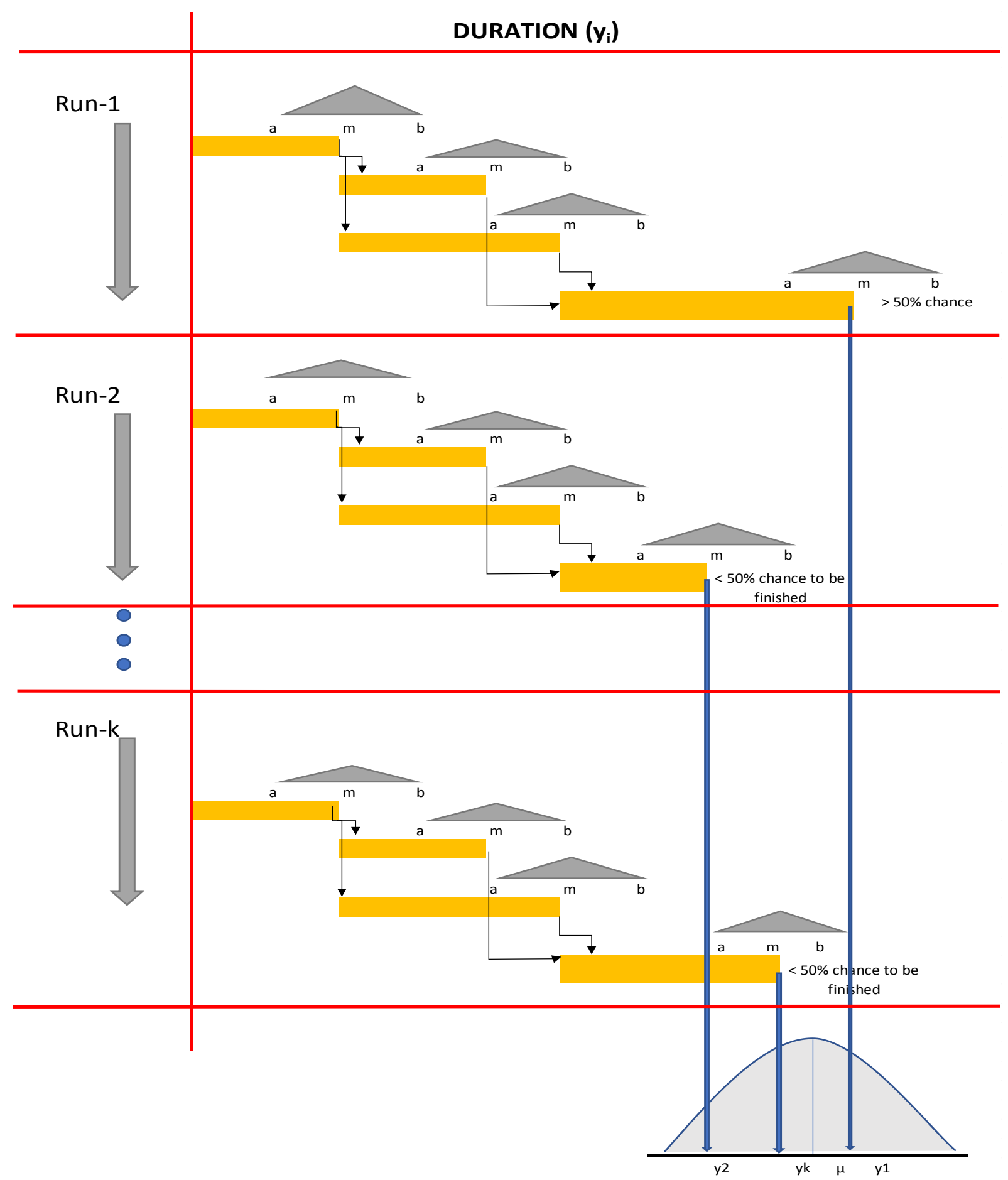

Figure 4: Example of Monte Carlo Simulation

Monte Carlo Simulation computes the obtained deterministic times for $k=9000$ iterations and over again according to end date for all possible uncertain activities to have more realistic final outcomes. Monte Carlo Simulation is taking the risk factor into an account that is why it is randomly generating the deterministic completion times for each activity for each trial. This step is repeated 9000 times as in Figure 4. In order to simulate all the possible outcomes, Monte Carlo Simulation giving for each trial different but very close final outcomes.

After the explanation of the Monte Carlo Simulation method, the following section will be about results and discussions for the establishment of Critical Path Method and Monte Carlo Simulation. 


\section{Results and Discussions}

In this section, after the establishment of Critical Path Method and Monte Carlo Simulation, the obtained values and conclusions will be mentioned. The table below shows the all activities with their predecessors and 3 different time measurement which will help to conduct Critical Path Method and Monte Carlo Simulation for Luxury Villa in result section of the article.

Table 1: Activities with durations of the Luxury Villa

\begin{tabular}{|c|c|c|c|c|c|c|c|c|c|c|c|c|c|}
\hline Activities & Activity Names & Predeccessor & $\mathbf{a}$ & $\mathbf{m}$ & $\mathbf{b}$ & TE & ES & $\mathbf{E F}$ & LS & LF & SL & $\sigma^{\wedge} 2$ & $\sigma$ \\
\hline 1.1 & Building Design & - & 4 & 7 & 10 & 7 & 0 & 7 & 0 & 7 & 0 & 1 & 1 \\
\hline 1.2 & Electrical Design & 1.1 & 2 & 3 & 4 & 3 & 7 & 10 & 8 & 11 & 1 & 0.33 & 0.11 \\
\hline 1.3 & Plmmbing Design & 1.1 & 2 & 4 & 6 & 4 & 7 & 11 & 7 & 11 & 0 & 0.67 & 0.44 \\
\hline 1.4 & Fine System Design & 1.1 & 1 & 2 & 3 & 2 & 7 & 9 & 9 & 11 & 2 & 0.33 & 0.11 \\
\hline 2.1 & Signing Project Contract & $1,2-1,3-1,4$ & 1 & 2 & 3 & 2 & 11 & 13 & 11 & 13 & 0 & 0.33 & 0.11 \\
\hline 2.2 & Project Permit & 2.1 & 2 & 3 & 4 & 3 & 13 & 16 & 14 & 17 & 1 & 0.33 & 0.11 \\
\hline 2.3 & Electirical Permit & 2.1 & 3 & 4 & 5 & 4 & 13 & 17 & 13 & 17 & 0 & 0.33 & 0.11 \\
\hline 2.4 & Plmmbing Permit & 2.1 & 2 & 3 & 4 & 3 & 13 & 16 & 14 & 17 & 1 & 0.33 & 0.11 \\
\hline 3.1 & Installation of Mobilization Building & $2,2-2,3-2,4$ & 3 & 5 & 7 & 5 & 17 & 22 & 17 & 22 & 0 & 0.67 & 0.44 \\
\hline 3.2 & Road Work & 3.1 & 2 & 3 & 4 & 3 & 22 & 25 & 22 & 25 & 0 & 0.33 & 0.11 \\
\hline 3.3 & Fence Work & 3.1 & 1 & 2 & 3 & 2 & 22 & 24 & 23 & 25 & 1 & 0.33 & 0.11 \\
\hline 4.1 & Cleaning and Grubling & $3,2-3,3$ & 1 & 3 & 5 & 3 & 25 & 28 & 25 & 28 & 0 & 0.67 & 0.44 \\
\hline 4.2 & Exavation & 4.1 & 4 & 7 & 10 & 7 & 28 & 35 & 28 & 35 & 0 & 1 & 1 \\
\hline 4.3 & Filling & 4.2 & 7 & 10 & 13 & 10 & 35 & 45 & 35 & 45 & 0 & 1 & 1 \\
\hline 5.1 & Pile & 4.3 & 6 & 11 & 16 & 11 & 45 & 56 & 45 & 56 & 0 & 1.67 & 2.78 \\
\hline 5.2 & Concrete & 5.1 & 7 & 9 & 11 & 9 & 56 & 65 & 60 & 69 & 4 & 0.67 & 0.44 \\
\hline 5.3 & Raft Foundation & 5.1 & 10 & 13 & 16 & 13 & 56 & 69 & 56 & 69 & 0 & 1 & 1 \\
\hline 6.1 & Colmmn and Curtain Wall & $5,2-2,3$ & 7 & 5 & 9 & 6 & 69 & 75 & 69 & 75 & 0 & 0.33 & 0.11 \\
\hline 6.2 & Slab & 6.1 & 2 & 4 & 6 & 4 & 75 & 79 & 76 & 80 & 1 & 0.67 & 0.44 \\
\hline 6.3 & Slab Insulation & 6.1 & 4 & 5 & 6 & 5 & 75 & 80 & 75 & 80 & 0 & 0.33 & 0.11 \\
\hline 6.4 & Masonary & 6.1 & 2 & 3 & 4 & 3 & 75 & 78 & 77 & 80 & 2 & 0.33 & 0.11 \\
\hline 6.5 & Upper Slab & 6.1 & 1 & 2 & 3 & 2 & 73 & 75 & 78 & 80 & 5 & 0.33 & 0.11 \\
\hline 7.1 & Colmmn and Curtain Wall & $6,2-6,3-6,4-6,5$ & 3 & 5 & 7 & 5 & 80 & 85 & 80 & 85 & 0 & 0.67 & 0.44 \\
\hline 7.2 & Slab & 7.1 & 3 & 4 & 5 & 4 & 85 & 89 & 86 & 90 & 1 & 0.33 & 0.11 \\
\hline 7.3 & Slab Insulation & 7.1 & 2 & 5 & 8 & 5 & 85 & 90 & 85 & 90 & 0 & 1 & 1 \\
\hline 7.4 & Masonary & 7.1 & 1 & 3 & 5 & 3 & 85 & 88 & 87 & 90 & 2 & 0.67 & 0.44 \\
\hline 7.5 & Upper Slab & 7.1 & 1 & 2 & 3 & 2 & 85 & 87 & 85 & 90 & 3 & 0.33 & 0.11 \\
\hline 8.1 & Roof Beam Installation & $7,2-7,3-7,4-7,5$ & 3 & 4 & 5 & 4 & 90 & 94 & 90 & 94 & 0 & 0.33 & 0.11 \\
\hline 8.2 & Roof Installation & 8.1 & 3 & 5 & 7 & 5 & 94 & 99 & 99 & 105 & 6 & 0.67 & 0.44 \\
\hline 8.3 & Roof Isolation & 8.1 & 1 & 3 & 5 & 3 & 94 & 97 & 96 & 99 & 2 & 0.67 & 0.44 \\
\hline 9.1 & Installation of Electric & $8,2-8,3$ & 4 & 6 & 8 & 6 & 99 & 105 & 99 & 105 & 0 & 0.67 & 0.44 \\
\hline 9.2 & Insallation of Plnmbing & $8,2-8,3$ & 3 & 5 & 7 & 5 & 99 & 104 & 100 & 105 & 1 & 0.67 & 0.44 \\
\hline 9.3 & Installation of Fine System & $8,2-8,3$ & 1 & 3 & 5 & 3 & 99 & 102 & 102 & 105 & 3 & 0.67 & 0.44 \\
\hline 10.1 & Drywall & $10,2-10,3$ & 6 & 10 & 14 & 10 & 117 & 127 & 117 & 127 & 0 & 1.33 & 1.78 \\
\hline 10.2 & Interior Brick Wall & $9,1-9,2-9,3$ & 11 & 12 & 13 & 12 & 105 & 117 & 105 & 117 & 0 & 0.33 & 0.11 \\
\hline 10.3 & Exterior Brick Wall & $9,1-9,2-9,3$ & 9 & 12 & 15 & 12 & 105 & 117 & 105 & 117 & 0 & 1 & 1 \\
\hline 11.1 & Plaster(ext-int) & 10.1 & 6 & 10 & 14 & 10 & 127 & 137 & 127 & 137 & 0 & 1.33 & 1.78 \\
\hline 12.1 & Travertine Coating & 11.1 & 9 & 11 & 13 & 11 & 137 & 148 & 137 & 148 & 0 & 0.67 & 0.44 \\
\hline 12.2 & Marble Coating & 11.1 & 5 & 7 & 9 & 7 & 137 & 144 & 141 & 148 & 4 & 0.67 & 0.44 \\
\hline 12.3 & Tile Mosaic Coating & 11.1 & 3 & 4 & 5 & 4 & 137 & 141 & 144 & 148 & 7 & 0.33 & 0.11 \\
\hline 12.4 & Ceramic Coating & 11.1 & 1 & 2 & 3 & 2 & 137 & 139 & 146 & 148 & 9 & 0.33 & 0.11 \\
\hline 12.5 & Epoxy & 11.1 & 1 & 2 & 3 & 2 & 137 & 139 & 146 & 148 & 9 & 0.33 & 0.11 \\
\hline 12.6 & Suspended Ceiling Cover & 11.1 & 5 & 8 & 11 & 8 & 137 & 145 & 140 & 148 & 3 & 1 & 1 \\
\hline 12.7 & Onter Wall Covering & 11.1 & 8 & 10 & 12 & 10 & 137 & 147 & 138 & 148 & 1 & 0.67 & 0.44 \\
\hline 13.1 & Fenestration Installation & $\begin{array}{l}12,1-12,2-12,3 \\
12,4-12,512,6\end{array}$ & 2 & 4 & 6 & 4 & 148 & 152 & 148 & 152 & 0 & 0.67 & 0.44 \\
\hline 13.2 & Wood Work & 13.1 & 4 & 5 & 6 & 5 & 152 & 157 & 153 & 158 & 1 & 0.33 & 0.11 \\
\hline 13.3 & Aliminnm Joinery & 13.1 & 3 & 6 & 9 & 6 & 152 & 158 & 152 & 158 & 0 & 1 & 1 \\
\hline 13.4 & Metal Joinery & 13.1 & 2 & 3 & 4 & 3 & 152 & 155 & 155 & 158 & 3 & 0.33 & 0.11 \\
\hline 14.1 & Interior Paint & $13,2-13,3-13,4$ & 3 & 4 & 5 & 4 & 158 & 162 & 158 & 162 & 0 & 0.33 & 0.11 \\
\hline 14.2 & Exterior Paint & 14.1 & 6 & 8 & 10 & 8 & 162 & 170 & 162 & 170 & 0 & 0.67 & 0.44 \\
\hline 15.1 & Ventilation System & 14.2 & 1 & 3 & 5 & 3 & 170 & 173 & 172 & 175 & 2 & 0.67 & 0.44 \\
\hline 15.2 & Clean-Waste Water & 14.2 & 4 & 5 & 6 & 5 & 170 & 175 & 170 & 175 & 0 & 0.33 & 0.11 \\
\hline 15.3 & Rain Water & 14.2 & 1 & 2 & 3 & 2 & 170 & 172 & 173 & 175 & 3 & 0.33 & 0.11 \\
\hline 15.4 & Mechanical Automation & $15,1-15,2-15,3$ & 1 & 3 & 5 & 3 & 175 & 178 & 175 & 178 & 0 & 0.67 & 0.44 \\
\hline 15.5 & Mechanical Electric Work & $15,1-15,2-15,3$ & 1 & 2 & 3 & 2 & 175 & 177 & 176 & 178 & 1 & 0.33 & 0.11 \\
\hline 16.1 & Fire Protection System & $15,4-15,5$ & 1 & 2 & 3 & 2 & 178 & 180 & 179 & 181 & 1 & 0.33 & 0.11 \\
\hline 16.2 & Fine Detection System & $15,4-15,5$ & 2 & 3 & 4 & 3 & 178 & 181 & 178 & 181 & 0 & 0.33 & 0.11 \\
\hline 16.3 & Security Ligthing & $15,4-15,5$ & 1 & 2 & 3 & 2 & 178 & 180 & 179 & 181 & 1 & 0.33 & 0.11 \\
\hline 17.1 & Cleaning & $16,1-16,2-16,3$ & 1 & 2 & 3 & 2 & 181 & 183 & 181 & 183 & 0 & 0.33 & 0.11 \\
\hline 17.2 & Final Control & 17.1 & 1 & 2 & 3 & 2 & 183 & 185 & 183 & 185 & 0 & 0.33 & 0.11 \\
\hline 17.3 & Delivery & 17.2 & 1 & 1 & 1 & 1 & 185 & 186 & 185 & 186 & 0 & 0 & 0 \\
\hline
\end{tabular}


Table above shows the times of each activities with their predecessors and ES, EF, LS, LF Slack time along with standard deviations and variances. Using this method, it is estimated project duration of 186 day for luxury villa construction.

The duration is obtained by summing all zero critical path activities.

Based on the Table 1, the Gantt Chart is constructed below and Figure 5 shows the total duration of the Luxury Villa as 186 days without analyzing risks which can alter the deterministic times obtained by CPM and PERT method.

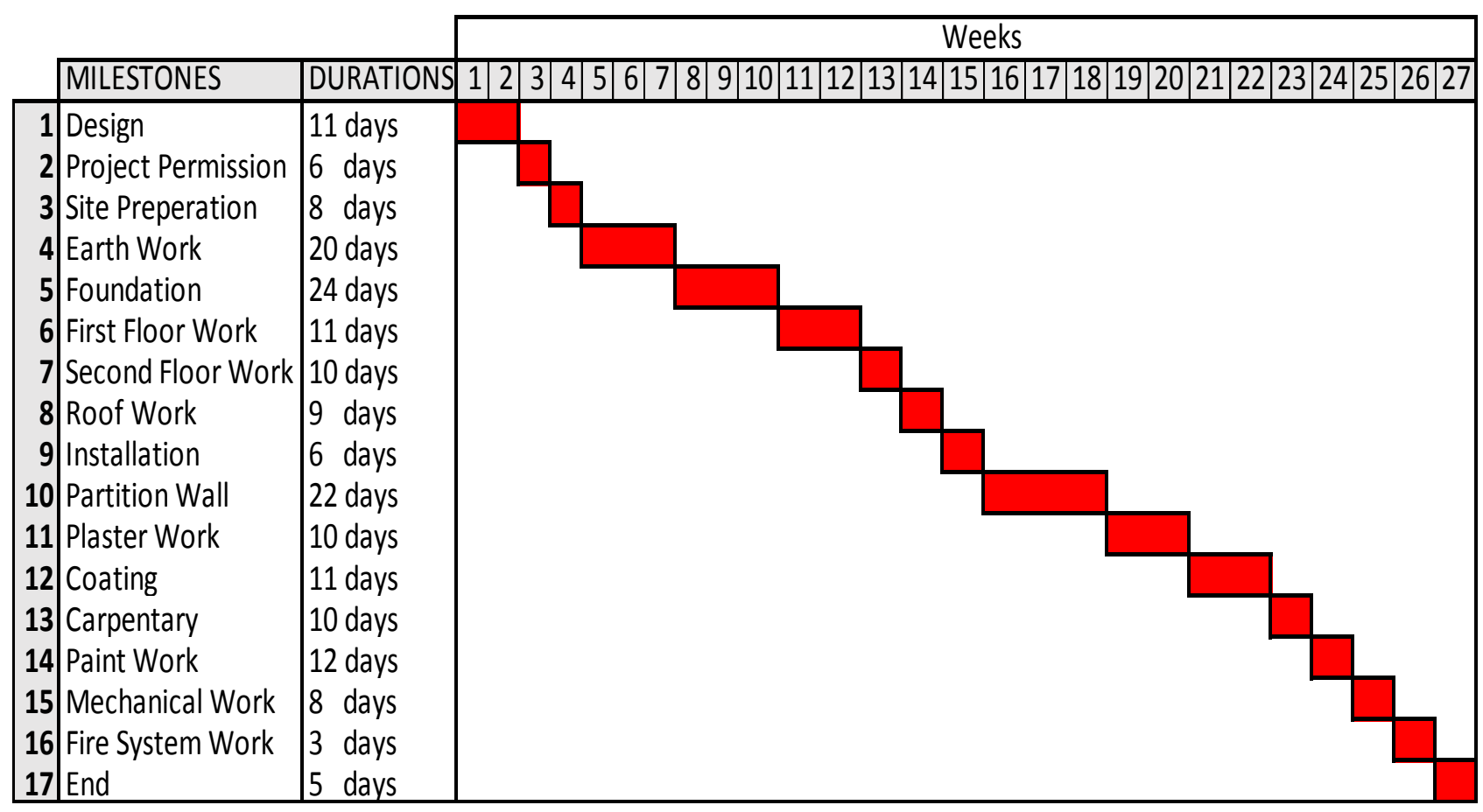

Figure 5: The Gantt chart of Luxury Villa

The Figure 5 above shows the Gantt Chart of the Luxury Villa. İt was conducted by using of 17 milestones of the construction. Milestones of the Luxury Villa is as follows, Design, Project Permissions, Site Preparation, Earth Work, Foundation, First Floor Work, Second Floor Work, Roof Work, Installations, Partition Wall, Plaster Work, Coating, Carpentry, Paint Work, Mechanical Work, Fire System Work and the End of the construction with total duration of 186 days which is equivalent to approximately 27 weeks.

In the process of establishment of the Critical Path method, all the times were taken and calculated were deterministic without risk considerations. 186 days was obtained, as if there will not be any obstacles which will change the time of the completion day of the Luxury Villa. Therefore, when all possible risks were taken account and identified carefully, there will be another probabilistic completion time for the construction of Luxury Villa. Those risks can vary, as internal risks, external risks, political risks, technological risks, natural risks and unexpectable risks.

There is a possible percentage for every risk which should be taken account. Because, these risks can be very significant in case of occurrence. But, it may also not occur. Figure 6 shows impact-probability risk analysis matrix. 


\begin{tabular}{|c|c|c|c|c|c|c|c|}
\hline \multirow{5}{*}{$\begin{array}{l}0 \\
0 \\
0 \\
\text { İ } \\
\frac{\vec{y}}{z}\end{array}$} & $\begin{array}{l}\text { Expected to occur regularly } \\
\text { under normal circumstances }\end{array}$ & $\begin{array}{l}\text { ALMOST } \\
\text { CERTAIN }\end{array}$ & $\begin{array}{l}\text { MANAGE AND } \\
\text { CONTROL RISK }\end{array}$ & $\begin{array}{l}\text { MANAGE AND } \\
\text { CONTROL RISK }\end{array}$ & $\begin{array}{l}\text { MUST TAKE } \\
\text { PRECAUTION }\end{array}$ & $\begin{array}{l}\text { MUST } \\
\text { MANAGE AND } \\
\text { MONITOR RISK }\end{array}$ & $\begin{array}{l}\text { MAKE } \\
\text { INSURANCE }\end{array}$ \\
\hline & Expected to occur some time & LIKELY & $\begin{array}{l}\text { ACCEPT BUT } \\
\text { MONITOR RISK }\end{array}$ & $\begin{array}{l}\text { MANAGE AND } \\
\text { CONTROL RISK }\end{array}$ & $\begin{array}{l}\text { MUST TAKE } \\
\text { PRECAUTION }\end{array}$ & \begin{tabular}{|l|} 
MUST \\
MANAGE AND \\
MONITOR RISK
\end{tabular} & $\begin{array}{l}\text { MAKE } \\
\text { INSURANCE }\end{array}$ \\
\hline & May Occur at some time & POSSIBLE & MONITOR RISK & $\begin{array}{l}\text { ACCEPT BUT } \\
\text { MONITOR RISK }\end{array}$ & $\begin{array}{l}\text { MONITOR } \\
\text { RISK }\end{array}$ & \begin{tabular}{|l|} 
MUST \\
MANAGE AND \\
MONITOR RISK
\end{tabular} & $\begin{array}{l}\text { MAKE } \\
\text { INSURANCE }\end{array}$ \\
\hline & $\begin{array}{l}\text { Not likely to Occur in normal } \\
\text { circumstances }\end{array}$ & UNLIKELY & ACCEPT RISK & $\begin{array}{l}\text { ACCEPT BUT } \\
\text { MONITOR RISK }\end{array}$ & $\begin{array}{l}\text { MONITOR } \\
\text { RISK }\end{array}$ & $\begin{array}{l}\text { CONSIDERABLE } \\
\text { MANAGEMENT } \\
\text { REQUIRED } \\
\end{array}$ & $\begin{array}{l}\text { EXTENSIVE } \\
\text { MANAGEMENT } \\
\text { REQUIRED }\end{array}$ \\
\hline & $\begin{array}{l}\text { Could happen but Probably } \\
\text { will never }\end{array}$ & RARE & ACCEPT RISK & $\begin{array}{l}\text { ACCEPT BUT } \\
\text { MONITOR RISK }\end{array}$ & $\begin{array}{l}\text { MUST } \\
\text { MANAGE AND } \\
\text { MONITOR RISK }\end{array}$ & \begin{tabular}{|l|} 
CONSIDERABLE \\
MANAGEMENT \\
REQUIRED
\end{tabular} & $\begin{array}{l}\text { MUST } \\
\text { MANAGE AND } \\
\text { MONITOR RISK }\end{array}$ \\
\hline & & & NOT SIGNIFICANT & MINOR & MODERATE & MAJOR & SEVERE \\
\hline & & & $\begin{array}{l}\text { 1)Wheather } \\
\text { Conditions } \\
\text { 2)Labor } \\
\text { Productivity } \\
\text { 3)Changes in } \\
\text { Project }\end{array}$ & $\begin{array}{l}\text { 1)Construction } \\
\text { Type } \\
\text { 2)Technology } \\
\text { used } \\
\text { 3) Equipment } \\
\text { Faults }\end{array}$ & $\begin{array}{l}\text { 1) Goverment } \\
\text { Pressure } \\
\text { 2)Ground } \\
\text { conditions } \\
\text { 3) Additional } \\
\text { Changes }\end{array}$ & $\begin{array}{l}\text { 1)Disease } \\
\text { 2) Political } \\
\text { Issues } \\
\text { 3) Erros of } \\
\text { Construction }\end{array}$ & $\begin{array}{l}\text { 1)Occupational- } \\
\text { Work Accident } \\
\text { 2) Naturel } \\
\text { Disaster } \\
\text { 3)Financial } \\
\text { Crisis }\end{array}$ \\
\hline & & & & PUI LIVI & UIVEL & NCES & \\
\hline
\end{tabular}

Figure 6: Risk Analysis for Luxury Villa

The table above represents the potential risks with their consequences and probability which directly affect the completion date of the project. After formation of the risk analysis table, now it will help to re-define completion date of the project with given risks.

Referring to Figure 6, the Occupational wok accidents, natural disasters and financial crisis were identified as the highest impact risks to the project. But the likelihood being happened is with catastrophic consequences is very rare, thus they are managed and monitored.

Disease, political issues and errors of construction were identified as major risk to the project. But the likelihood being happened is with fatal consequences is unlikely, thus they are managed and monitored.

Government pressure, ground conditions and additional changes were identified as moderate risk to the project. However, the likelihood being happened is with hazard is possible, thus precautions are taken into consideration.

Construction type, technology used and equipment faults were identified as minor risks to the project. But the likelihood being happened is with significant consequence is very likely thus, risks must be accepted and monitored.

Weather conditions, labor productivity and changes in project were identified as not significant risks. However, the likelihood being happened is with insignificant consequences are very low thus, the risks must be accepted.

By Monte Carlo Simulation, it will be easy to identify the risks of completion project on time, and comparing the result to PERT/CPM. The table below is called Risk Analysis for the construction of the Luxury Villa with a precaution. The result of Monte Carlo simulation is represented using probability density function and cumulative density function and shown in Figure 7. 


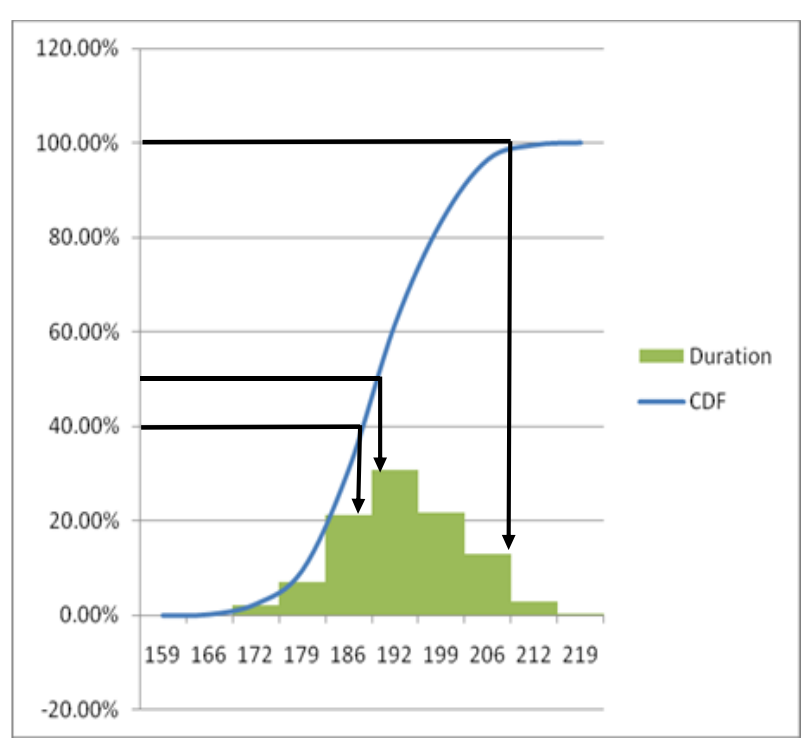

\begin{tabular}{|r|c|r|l|}
\hline \multicolumn{1}{|l|}{ Duration } & \multicolumn{1}{|l|}{ lreq } & \multicolumn{1}{l|}{ PDF } & \multicolumn{1}{l|}{ CDF } \\
\hline 157 & 1 & $0.01 \%$ & $0.01 \%$ \\
\hline 164 & 6 & $0.07 \%$ & $0.08 \%$ \\
\hline 171 & 71 & $0.79 \%$ & $0.87 \%$ \\
\hline 178 & 543 & $6.07 \%$ & $6.95 \%$ \\
\hline 185 & 1722 & $19.26 \%$ & $26.21 \%$ \\
\hline 191 & 2752 & $30.78 \%$ & $56.98 \%$ \\
\hline 198 & 2425 & $27.12 \%$ & $84.11 \%$ \\
\hline 205 & 1104 & $12.35 \%$ & $96.45 \%$ \\
\hline 212 & 277 & $3.10 \%$ & $99.55 \%$ \\
\hline 219 & 40 & $0.45 \%$ & $100.00 \%$ \\
\hline
\end{tabular}

Figure 7: Results of Monte Carlo Simulation

The probability of finishing the construction in 186 days as it determined by CPM is about $38 \%$, in 190 days is about 50\% and in 205 days is approximately 100\% according to Monte Carlo Simulation. These results show more realistic values since CPM and PERT did not consider the possible risks which may happen during the construction phases.

\section{Conclusion}

Two different method were used in order to make comparison between Monte Carlo simulation and Critical Path Method. As it can be understandable, Monte Carlo simulation is giving more realistic outcomes. When Critical Method is compared with Monte Carlo simulation, it is seen that, by the establishment of risk analysis, it is giving better control over monitoring and identifying the risks. Another conclusion is obtained is, according to Critical Path method, the completion date of the Luxury Villa was 186 days (which is optimistic estimate). After the establishment of Monte Carlo simulation, by taking an account of risks, it gave about $38 \%$ for 186 days, about $50 \%$ for 190 days and approximately $100 \%$ for 205 days for completion date of the Luxury Villa along with uncertainty about $50 \%$ of chance which implies that Luxury Villa may be delayed.

\section{References}

[1] Ramo Palalic, Benjamin Durakovic, Azra Brankovic and Ognjen Ridic, "Students' entrepreneurial orientation intention, business environment and networking: insights from Bosnia and Herzegovina," International Journal of Foresight and Innovation Policy, vol. 11, no. 4, pp. 240-255, 2016.

[2] Benjamin Durakovic and Muris Torlak, "Experimental and numerical study of a PCM window model as a thermal energy storage unit," International Journal of Low-Carbon Technologies , vol. 12, pp. 272-280, 2016.

[3] M. Torlak, B. Durakovic, H. Gabranovic and N. Delalic, "CFD-Based Assessment of Thermal Energy Storage in Phase-Change Materials (PCM)," ENTECH_2014, no. 1, pp. 263-275, 2014.

[4] Benjamin Durakovic and Muris Torlak, "Simulation and experimental validation of phase change material and water used as heat storage medium in window applications," Journal of Materials and Environmental Sciences ISSN : 2028-2508, vol. 8, no. 5, pp. 1837-1846, 2017.

[5] H. Basic, B. Durakovic and A. Softic, "Six Sigma Model Testing in Optimizing Medium-Sized Company Production Process," Journal of Trends in the Development of Machinery and Associated Technology, vol. 16, no. 1, pp. 103-106, 2012. 
[6] W. Agyei, "Project Planning And Scheduling Using PERT and CPM Techniques With Lineer Programming," vol. 4, pp. 222-223, 2015.

[7] B. Durakovic, H. Basic and H. Muhic, "The Interrelationships Between Quality Management Practices and Their Effects on Innovation Performance," Trends in the Development of Machinery and Associated Technology TMT 2014, pp. 181-184, 2014.

[8] B. Durakovic and H. Basic, "Continuous Quality Improvement in Textile Processing by Statistical Process Control Tools: A Case Study of Medium-Sized Company," Periodicals of Engineering and Natural Sclences, vol. 1, no. 1, pp. 39-46, 2013.

[9] B. Durakovic and H. Basic, "Textile Cutting Process Optimization Model Based on Six Sigma Methodology in A Medium-Sized Company," Journal of Trends in the Development of Machinery and Associated Technology, vol. 16, no. 1, pp. 107-110, 2012.

[10] Duncan Haughey, Project Management Tools, 2015.

[11] G. Hagan, Glossary of Defense Acquisition Acronyms and Terms: Contract Work Breakdown Structure $(C W B S)$, vol. 13, Fort Belvoir, Virginia: Defense Acquisition University Press", 2017.

[12] M. W.NEWELL and M. N. Grashina, "The project Management Question and Answer," p. 68.

[13] S. J. Mantel and J. R.Meredith, "Network Techniques: PERT (ADM) and CPM (PDM)," in Project Management, A Managerial Approach Seventh Edition, United States of America, John Wiley \& Sons, 2009, pp. 343-344.

[14] "www.investopedia.com/terms/s/swot.asp," [Online].

[15] K. Zhaoni , Z. Jianping , L. Chao , Z. Xiaoying and Q. , "Risk Assessment of Plan Schedule by Monte Carlo Simulation," pp. 509-510, 2015. 